\title{
CONTRIBUTION A L'ÉTUDE DE LA QUALITÉ DES ODEURS DE LA « VIANDE » DE PORC
}

\author{
B.-L. DUMONT et B. DESMOULIN* \\ Laboratoire de Recherches sur la Viande, \\ * Station de Recherches sur l'Élevage des Porcs, \\ Centre national de Recherches zootechniques, I. N.R. A, \\ 78350 Jouy en Josas
}

\section{RÉSUMÉ}

Pour détecter à l'abattage la présence d'odeur sexuelle ou d'odeurs désagréables chez des porcs mâles entiers et des animaux castrés tardivement de race Large-White, on a effectué le contrôle des odeurs de différents tissus (gras dorsal, gras périrénal, gras mésentériquc, gras inguinal, glande sous-maxillaire et glande parotide, sérum sanguin) chauffés à l'étuve à $80^{\circ} \mathrm{C}$ pendant une heure.

On a trouvé que tous les tissus étaicnt, plus ou moins, affectés par l'odeur sexuelle et (ou) par des odeurs déplaisantes d'autre origine. Il n'y avait pas de rapport entre les odeurs déplaisantes des tissus gras ou des glandes et l'odeur manifestée par la viande pendant la cuisson, même quand une odeur sexuelle désagréable était détectée, soit dans le gras mésentérique, soit dans le gras périrénal.

Il semble important d'apporter beaucoup d'attention dans le futur, aux odeurs des viandes et graisses de porc. On souligne dans ce rapport la necessité de procéder à la détermination de " profil d'odeurs " pour définir avec précision la qualité des caracasses de porcs de différents types.

\section{SUMMARY}

\section{PORK ODOUR AND BOAR TAINT IN PIGS}

The control of odours of various tissues (backfat, kidney fat, mesenteric fat, inguinal fat, submaxillary and parotid glands, blood serum) heated in dry state at $80^{\circ} \mathrm{C}$ during one hour has been performed in order to detect at slaughter (or in vivo) boar taint and unpleasant odours in young boars and late castrated pigs.

It was found that all the tissues considered were more or less affected by boar taint and (or) unpleasant odours. There was no relationship between unpleasant odours of fatty or glandular 
tissues and unpleasant odour of meat cuts during cooking, even when boar taint was detected as objectionable in mesenteric or in kidneyfat.

It seems important to put much attention, in the future, to the odours of pork (boar taint or, mainly, "pig taint ". The need for determination of "odour profile ", such it has been stated in this study, is emphasized to define more precisely the carcass quality of pigs.

\title{
CARACTÈRES de CLASSIFICATION DES CARCASSES DE PORCS ISSUS DE CROISEMENTS « COMMERCIAUX »
}

\author{
B. DESMOULIN, F. POLINE et Y. MAURY
}

\author{
Station de Recherches sur l'Élevage des Porcs, \\ Centre national de Recherches zootechniques, I. N.R. A., \\ 78350 Jouy en Josas \\ Établissements Sanders, \\ 91 - Juvisy-sur-Orge
}

\section{RÉSUMÉ}

60 carcasses de pores issus de trois types de croisements commerciaux $\mathrm{T}$, P et H sont étudiées comme échantillon représentatif du classement commercial (I. T. P) établi en abattoir industriel sur 300 porcs (produits par les établissements Sanders). Après la découpe normalisée des demicarcasses, la densité des morceaux séparés : jambon, "rein de porc " ou ensemble longe + bardière, poitrine hachage et jambonneau, est déterminée au C. N. R. Z. selon les méthodes définies antérieurement (Desmoulin, r97o). Des abaques de classification sont construites suivant le caractère de densité du "rein de porc " (DESmOulin et BouRDON, I971) : elles définissent une répartition individuelle des carcasses dans 6 classes d'état d'engraissement comprises entre r,030-1,035 (classe I) et I,055-I,060 (classe VI). Les caractères associés à cette discrimination suivant la densité sont ainsi précisés pour les porcs gras et pour les porcs maigres.

I. L'épaisseur du lard dorsal est un critère de différenciation des porcs gras (classes I à III) alors que la longueur de carcasse est un caractère discriminant des porcs maigres (classe III à VI). La sélection des porcs maigres, sur le critère d'épaisseur du lard dorsal, est ainsi limitée. Toutefois, sur ces deux caractères, on note une influence marquée du type génétique : le type $\mathrm{H}$ présente ainsi une carcasse très courte avec des masses maigres globuleuses caractéristiques d'un porc maigre de type "culard ". Le type $\mathrm{P}$ présente inversement une carcasse très longue sans présenter toutefois une adiposité (poids de bardière) très réduite et des masses maigres très développées ; c'est un porc de type "baconer ". La limite des caractères de conformation des carcasses est ainsi précisée : la longueur de carcasse doit être associée à l'épaisseur du lard dorsal.

2. La densité du " rein de porc ", très représentative de l'état d'engraissement de la carcasse totale (sans pieds, ni tête), permet de justifier l'utilisation du rapport longe/bardière comme caractère simple d'estimation de l'état d'engraissement des carcasses. Cependant, la faible reproductivité des résultats de la découpe est mise en évidence : la séparation non aléatoire des masses maigres, longe, et des masses grasses, bardière, conduit à majorer de $r, 5$ points le pourcentage 